\title{
O eclipse solar de maio de 1919 e as relações científicas entre Brasil e Inglaterra
}

\section{The May 1919 Solar Eclipse and Scientific Relations Between Brazil and England}

\author{
Sofia Guilhem Basilio \\ Doutoranda em Ensino de Física \\ pelo Programa Interunidades \\ em Ensino de Ciências da \\ Universidade de São Paulo \\ sofia.basilio@usp.br
}

Recebido em: 31/01/2020

Aceito em: 22/04/2020

\section{Resumo}

O eclipse solar de 1919 é um importante episódio dentro da História da Física. Sua complexidade e as várias nacionalidades envolvidas permitem diversas análises, ainda mais se observarmos para além das regionalidades, olhando as interrelações das diversas comunidades científicas. Pretendemos nesse artigo focar nas relações entre as equipes brasileira e inglesa que se dirigiram para Sobral. Apresentamos como Henrique Morize foi importante para a escolha de Sobral e seu relacionamento com os astrônomos britânicos. Trabalhamos sobre a preparação de ambos os comitês, abordando quais foram as motivações das equipes e a forma como comunidades científicas e órgãos governamentais se relacionavam.

Palavras-chave: Eclipse, Sobral, Teoria da Relatividade, Expedição Inglesa, Observatório Nacional

\section{Abstract}

The solar eclipse of 1919 is an important episode within the History of Physics. Its complexity and the various nationalities involved allow for multiple analyzes, especially if we look beyond the regionalities, observing the interrelationships of the various scientific communities. We intend in this paper to focus on the relations between the Brazilian and English teams that went to Sobral. We present how Henrique Morize was important for Sobral's choice and his relationship with British astronomers. We worked on the preparation of both committees, addressing the motivations of the teams and the way scientific communities and government agencies were related.

Keywords: Eclipse, Sobral, Theory of Relativity, English Expedition, National Observatory 


\section{Introdução}

No final de novembro de 1919, algumas semanas após o grande anúncio que até hoje é considerado por muitos como a comprovação da Teoria da Relatividade Geral, o Astrônomo Real Frank Dyson escreveu as seguintes palavras:

Pela minha própria experiência em Expedições de Eclipses, eu sei as dificuldades, e entendo que um sucesso em grande escala depende da boa vontade e da assistência voluntária oferecida aos observadores. No Brasil nada lhes faltou, e isso se deu principalmente da excelente maneira como você, como um Astrônomo, conseguiu entregar com vigor as generosas provisões do Governo Brasileiro (DYSON, 1919, p. 1, tradução nossa)

As gentis palavras acima traduzidas se dirigiam ao diretor do Observatório Nacional do Rio de Janeiro, Henrique Morize, gentileza essa que aponta para uma rica relação entre as comunidades astronômicas inglesa e brasileira, aflorada na época em que fenômenos astronômicos estavam prestes a acontecer.

O motivo do agradecimento feito por Dyson a Morize está relacionado com um relevante eclipse do Sol que foi visível em sua totalidade em solo brasileiro: o eclipse de 29 de maio de 1919. Esse eclipse foi de extrema importância para a História da Ciência como um todo, alterando a maneira como cientistas e não-cientistas se relacionavam com os conceitos de espaço e de tempo.

O episódio do eclipse de 1919 pode ser analisado a partir de várias perspectivas, graças ao período histórico no qual os agentes envolvidos estão inseridos - os primórdios do século XX e fim da Primeira Guerra Mundial - além da farta documentação referente ao planejamento, desenvolvimento, análise de dados e divulgação dos resultados. Juntamente com esses fatores, um ponto importante para o propósito do presente artigo é a confluência em torno da observação desse eclipse de diversos astrônomos, de diversas nacionalidades, em contextos sociais distintos e muito particulares.

A história em torno do eclipse já foi fartamente explorada, principalmente no ano de 2019, quando se completaram cem anos de sua observação. Dois exemplos nacionais da importância de tal evento histórico foram realizados pela Sociedade Brasileira Para o Progresso da Ciência, ambos focados na pesquisa acadêmica acerca do tema, mas também na divulgação de sua relevância histórica: o primeiro foi a publicação da revista Ciência \& Cultura, volume 71, número 3, que teve como núcleo temático o centenário do eclipse. O segundo exemplo foi o evento gratuito do Centenário do Eclipse de Sobral, realizado entre os dias 28 e 30 de maio de 2019 na própria cidade, que contou com palestras de físicos e historiadores da ciência, além da reinauguração do Museu do Eclipse, que estava fechado e passando por reformas desde 2016.

Contudo, mesmo já tendo sido amplamente explorado, esse evento histórico apresenta outras possibilidades de análise, particularmente quando pensamos para além de uma análise puramente regional, nos focando nas interrelações que as diversas comunidades astronômicas estabeleceram para a observação do eclipse, analisando as formas como tais relações foram estabelecidas e o papel que cada uma das equipes de diferentes nacionalidades desempenhou para que Sobral se tornasse um importante ponto dentro do escopo da História da Ciência. Com isso, pretendemos aqui nos focar nas relações entre as equipes brasileira e inglesa que se dirigiram para Sobral, além de compreendermos quais foram os impactos que essas expedições causaram em cada um de seus respectivos contextos geográficos.

Primeiramente, iremos apresentar de modo muito sucinto como o trabalho de Albert Einstein a respeito da Teoria da Relatividade Geral publicado em 1916 foi crucial para que a equipe inglesa tivesse interesse em organizar uma expedição para a observação do evento astronômico de maio de 1919 e como o astrônomo brasileiro Henrique Morize tem um papel central para a determinação de Sobral como o local mais adequado em solo brasileiro para a sua observação. Trabalharemos como se deu a preparação de ambos os comitês para a observação do eclipse, apresentando os desafios que cada um dos contextos impôs aos cientistas e como tais desafios foram superados por eles. Por fim, também abordaremos no presente 
artigo quais eram as motivações das equipes que transformaram o eclipse do dia 29 de maio de 1919 em um evento relevante não só no âmbito puramente científico pelos resultados que foram obtidos a partir dele, mas também como essas motivações dizem respeito à forma como comunidades científicas e órgãos governamentais se relacionavam.

\section{A Teoria da Relatividade Geral e um Novo Desafio}

O ano de 1905 é conhecido até hoje como "o ano milagroso" de Albert Einstein. De março até dezembro, foram apresentados seis artigos referentes a problemas centrais do início do século XX (PAIS, 1993). Porém, para o episódio no qual estamos aqui nos debruçando, dois artigos publicados posteriormente, um em 1911 e outro em 1916, são os mais relevantes devido às previsões que continham.

Em junho de 1911 foi publicado no Annalen der Physik o trabalho intitulado Über den Einfluß der Schwerkraft auf die Ausbreitung des Lichtes. Na terceira parte desse artigo, Einstein conduz um experimento mental iniciado com um par de relógios idênticos produzidos em uma região pequena do espaço cujo campo gravitacional é constante. Ao aplicar o resultado desse Gedankenexperiment à deflexão de um raio de luz devido ao campo gravitacional do Sol, Einstein obtém uma deflexão igual a $\alpha=0,83$ ". Ele finaliza seu artigo dizendo que é "urgente que os astrônomos aceitem a questão levantada, mesmo que as considerações dadas anteriormente não tenham sido suficientemente fundadas ou mesmo aventureiras" (EINSTEIN, 1911, p. 908, tradução nossa).

Esse valor para a deflexão da luz foi posteriormente corrigido em 1916. Uma das principais modificações que ocorreu entre esses trabalhos foi a maneira como o espaço era conceitualizado por Einstein. Em 1911 ele ainda utilizava a noção de espaço plano e, em 1916, com a adoção da teoria de Riemann, Einstein corrigiu a previsão para a deflexão da luz nas proximidades do Sol no seu artigo Die Grundlagen der allgemeinen Relativitätstheorie. Agora, um "raio de luz que passa pelo Sol experimenta [..] uma curvatura de 1,7"' (EINSTEIN, 1916, p. 822, tradução nossa). Com essa predição, o desafio da realização de testes observacionais que pudessem validar (ou não) a nova teoria e a nova conceitualização do próprio espaço foi entregue aos astrônomos do final da década de 1910 (KEVLES, 2005).

Contudo, o desafio não foi prontamente recebido pelos físicos e astrônomos que estavam fora da Alemanha - mais precisamente, por aqueles que não estivessem em algum dos países constituintes da Tríplice Aliança. Einstein enfrentou diversos problemas para que seu artigo fosse lido por colegas de outras nacionalidades graças ao contexto da Primeira Guerra Mundial. Entre os desafios enfrentados estava a forte propaganda de guerra feita pelos ingleses contra seus inimigos (BROWN, 1963; MARQUIS, 1978), o que, juntamente com outros fatores referentes a atos cometidos no período da guerra - o uso de armas químicas na segunda batalha de Ypres, ou mesmo o "Manifesto dos 93", onde intelectuais germânicos defendiam os militares alemães, retrucando as acusações de crimes de guerra durante a invasão da Bélgica - resultou na cisão da comunidade científica, cuja intensidade levou uma parte dos próprios cientistas a acreditar que a colaboração com cientistas de nações rivais estava indefinidamente impossibilitada (KEVLES, 2005).

Os efeitos dos bloqueios entre as nações envolvidas na guerra se deram logo após seu início, inclusive no âmbito científico. Já em agosto de 1914, os astrônomos britânicos percebiam que algo estranho estava acontecendo:

A edição mais recente que alguém tinha da Astronomishe Nachrichten - o principal jornal germânico de astronomia - era datado de 22 de julho. Certamente houve um volume mais recente? Não houve. As trincheiras cortaram a comunicação científica tão eficientemente como cortaram o comércio. O bloqueio britânico manteve fora as revistas científicas, juntamente com propaganda prussiana e cartas pessoais (STANLEY, 2019, p. 117-118, tradução nossa) 
Ficam assim visíveis as razões para o baixo impacto das publicações de periódicos alemães fora do contexto germânico no período. Embora a recepção do trabalho de Einstein tenha sido distinta dependendo do local que está sob o foco da análise, não podendo ser generalizada em uma única forma (GLICK, 1987), é seguro afirmar que, com exceção do contexto germânico, boa parte dos debates acerca da teoria só ocorreram após a divulgação dos resultados obtidos a partir da observação do eclipse de 1919. "Na Inglaterra, assim como em outros lugares, a relatividade só rompeu [as barreiras] depois de 1919, agora com Eddington como a fonte da teoria" (KRAGH, 2002, p. 102, tradução nossa).

$\mathrm{O}$ astrônomo inglês Arthur Eddington teve contato com a Teoria da Relatividade Geral a partir de Willem de Sitter, físico e matemático holandês, que conseguiu cópias do artigo original de Einstein por se encontrar na Holanda, país neutro na Primeira Guerra Mundial. De Sitter submeteu dois artigos em 1916 sobre a relatividade geral para a Monthly Notices of the Royal Astronomical Society, onde são apresentados tanto os princípios desenvolvidos por Einstein em seu artigo de 1916 (incluindo a predição feita para a deflexão de um raio de luz ao passar na proximidade do Sol) quanto algumas contribuições do próprio de Sitter à teoria. Além da publicação desse par de artigos, de Sitter também enviou algumas cópias do artigo original de Einstein para Eddington como demonstração da amizade pessoal que existia entre eles, sendo essas "as únicas cópias dos artigos de Einstein disponíveis na Bretanha ou nos Estados Unidos até o fim da guerra" (CHANDRASEKHAR, 1976, p. 251, tradução nossa).

Porém, a empolgação e aceitação de Eddington a respeito da Teoria da Relatividade Geral não eram posicionamentos unânimes entre seus pares. Muitos fatores foram determinantes para a pouca penetração da teoria einsteiniana na Inglaterra. Como já explicitado, a extrema dificuldade dos cientistas ingleses a terem acesso aos periódicos de países inimigos; a falta de evidências experimentais da teoria; as técnicas matemáticas utilizadas, pouco compreendidas pela maioria dos cientistas da época; o abandono do éter - o que havia se iniciado por parte de Einstein já em 1905 - conceito esse no qual os físicos britânicos há muito se apoiavam e relutavam em abandonar (KRAGH, 2002); o alto grau de abstração presente no trabalho, que gerava suspeita entre os pares e representava uma mudança epistemológica brusca com relação à maneira como os fenômenos eram conceitualizados pelos físicos no início do século XX:

Tradicionalmente, os físicos adotavam uma visão mecânica da natureza, tentando explicar os fenômenos em termos de sistemas como o éter, que eles tomavam por ser entidades mecânicas reais, mesmo que invisível para nossos sentidos diretos. Princípios e leis tinham um papel na sua ciência, mas não como postulados. Eles poderiam apenas ser aceitos provisoriamente, sendo dependentes de provas empíricas. Einstein parecia inverter as práticas normais da física. Ele fez o princípio em uma lei e exigiu que o éter fosse eliminado porque não podia ser visto, deixando assim o campo eletromagnético sem nenhuma base material. É por isso que se vê tantas queixas sobre Einstein ter rejeitado o senso comum e propondo conceitos obscuros (KENNEFICK, 2019, p. 98, tradução nossa)

O próprio posicionamento político de Eddington a respeito da Grande Guerra foi relevante no desenrolar da preparação da expedição para o eclipse de 1919. O fato de ele ser um objetor de consciência influenciava diretamente sua reputação, dentro e fora do âmbito acadêmico. Esse posicionamento político, muito rejeitado no período, em conjunto com o fato de ser um dos únicos defensores da teoria de Einstein dentro do âmbito científico inglês, o colocou em uma minoria dentro da comunidade astronômica, com a qual ele necessitou se aliar para que a expedição ocorresse.

\section{O Desenvolvimento das Expedições}

Apesar de Eddington ser até hoje considerado o grande entusiasta da astronomia britânica por trás do desenvolvimento da expedição de 1919, juntamente a ele encontravam-se alguns influentes nomes da época, figurando entre eles Frank Dyson. Dyson foi Astrônomo Real entre os anos de 1910 e 1933 e, nos 
anos da preparação da expedição inglesa, se tornou um elo importante entre Eddington e as sociedades científicas britânicas.

A primeira proposta apresentada a Royal Astronomical Society acerca das potencialidades do eclipse de 1919 para a verificação da teoria da gravidade de Einstein foi feita por Dyson em 2 de março de 1917. Nessa proposta, Dyson (1917, p. 446, tradução nossa) defendeu que, na ocasião do evento astronômico, haveria "um número incomum de estrelas brilhantes e [...] não menos de treze estrelas podem ser obtidas". No dia 10 do mesmo mês, na reunião anual do Joint Permanent Eclipse Committee (JPEC) - grupo conjunto criado entre a Royal Society e a Royal Astronomical Society em 1892 para facilitar a organização de expedições inglesas para a observação de eclipses e cujo presidente na época, coincidentemente, era Dyson - foram determinados Sobral e Ilha Príncipe como possíveis locais para a observação do eclipse de 1919 (DYSON; EDDINGTON; DAVIDSON, 1920).

Contudo, um ponto que é interessante de nota: os possíveis locais de observação não constam na proposta apresentada por Dyson a Royal Astronomical Society, tendo em vista o desfecho de seu texto.

Isso [as possíveis treze estrelas observáveis] deve servir para uma ampla verificação, ou o contrário, da teoria de Einstein. Infelizmente, o trajeto do eclipse é através do Atlântico e perto do Equador. O Sr. Hinks gentilmente comprometeu-se a obter para a Sociedade informações sobre as estações que podem ser ocupadas. Apresentei o assunto para que providências para observar no maior número possível de estações possam ser tomadas o mais cedo possível (DYSON, 1917, p. 447, tradução nossa).

No relatório redigido após a expedição, Dyson, Eddington e Davidson (1920) nos apresentam que, dentre os possíveis locais apontados por Hinks para a observação, além de Sobral e Ilha do Príncipe, existiam também as estações de Cabo Palmas e do Lago Tanganyika, mas essas últimas foram descartadas por conta de relatórios meteorológicos e localizações geográficas não tão favoráveis.

Porém, a escolha de Sobral como um local de observação, além de uma decisão técnica, também representa as relações entre a comunidade científica britânica e brasileira. "Uma circular recebida de Dr. MORIZE, o diretor do Observatório no Rio, declarava que Sobral era a estação mais adequada no Norte do Brasil e deu copiosa informação das condições meteorológicas, formas de acesso etc." (DYSON; EDDINGTON; DAVIDSON, 1920, p. 295, tradução nossa). Eddington e Davidson, que assinam esse texto ao lado de Dyson, já conheciam o Dr. Morize de outra expedição inglesa que veio ao solo brasileiro em 1912.

\section{Morize e o contato com os ingleses}

Henrique (ou Henri) Charles Morize, de origem francesa, chegou ao Brasil em 1875 aos seus 14 anos, após o falecimento de seus pais, acompanhado de sua tia, sua avó materna e seu irmão. Morize começou seus trabalhos no Observatório Nacional ${ }^{1}$ em 1884, sendo diretor da instituição entre os anos de 1908 até 1929.

A cooperação entre as equipes brasileira do Observatório Nacional e inglesa do Observatório de Greenwich para a observação de eventos astronômicos não se inicia em 1919, já que, no final de maio de 1912, outro eclipse solar visível em solo brasileiro atraiu expedições de diversos países. Arthur Eddington, Charles Davidson e John Atkinson foram para Passa Quatro, em MG, para fotografar a coroa solar, realizar observações espectroscópicas e verificar a existência do coronium, encontrando-se ali com a equipe do Observatório Nacional, composta por Morize, Domingos Costa, Mário de Souza, Alix Lemos e Gualter de Macedo Soares, que objetivavam fotografar a coroa solar e realizar observações magnéticas (BARBOZA, 2010).

1 O Observatório Nacional, fundado em 1827 como Observatório Astronômico, passou ao longo de sua história por diversas renomeações, tendo o seu atual nome definido em 1909. 
Morize esperava que, com a participação no evento astronômico de 1912, ele e sua equipe pudessem demonstrar para o governo e para a elite brasileira a relevância da astronomia e o papel fundamental que o observatório desempenhava.

[O] observatório, raríssimas vezes, tinha desfrutado de uma situação material adequada para que desempenhasse satisfatoriamente suas tarefas. A ciência e, em particular, a astronomia, não eram vistas pelo governo federal ou pela chamada elite social e cultural como constituindo elementos relevantes, seja para melhorar a vida da população, seja para aumentar o conhecimento em geral (VIDEIRA, 2019, p. 23)

Apesar do resultado infrutífero das observações do eclipse de maio de 1912 devido ao mau tempo, o contato entre Morize e a equipe do Observatório de Greenwich já havia sido estabelecido. Através do relatório enviado por Morize, a equipe inglesa determinou Sobral como um dos locais de observação do eclipse de 1919, além de possibilitar à equipe do Observatório Nacional a preparação e recepção das equipes estadunidense ${ }^{2}$ e inglesa em Sobral.

\section{A preparação da expedição inglesa}

A trilha para a observação da totalidade do eclipse solar de maio de 1919 saía do nordeste brasileiro, atravessando o Atlântico até a costa africana, passando por Ilha do Príncipe e adentrando no continente, chegando até o Lago Tanganyika.

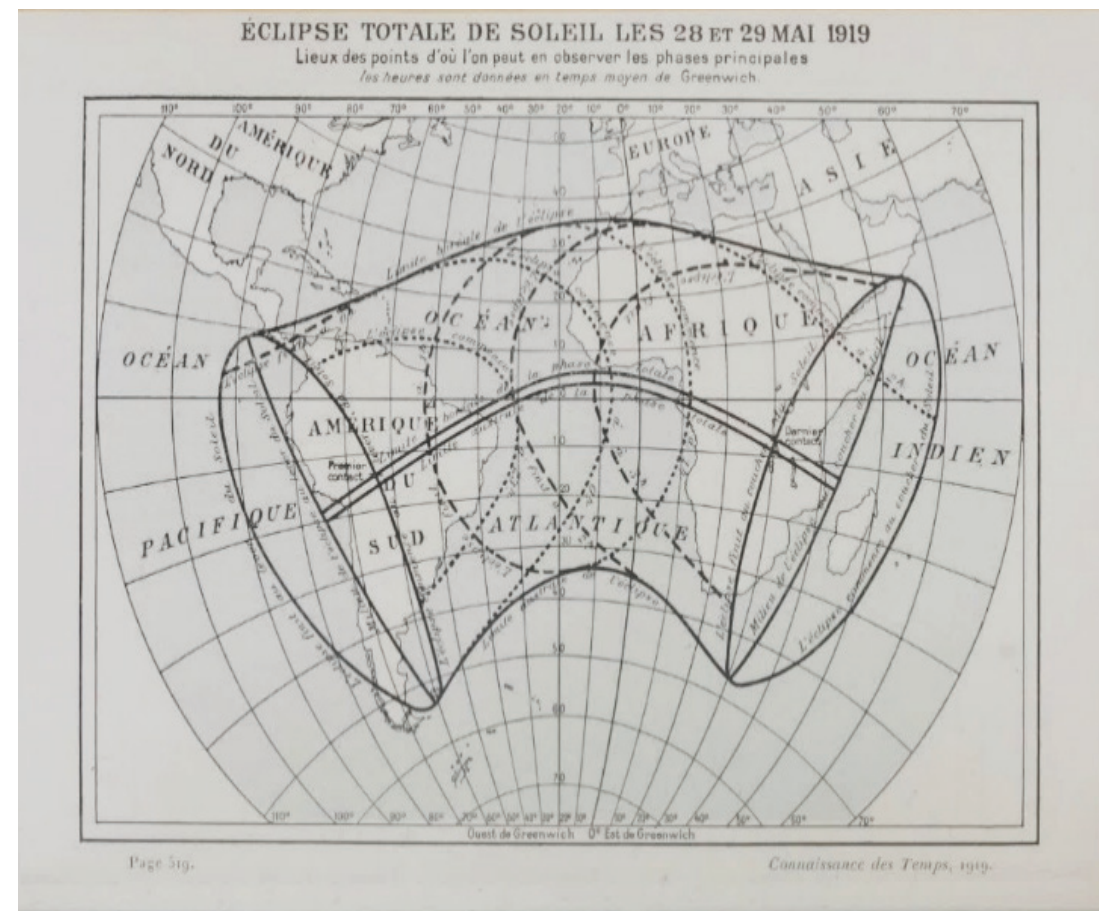

Figura 1 - Trajetória do eclipse de 1919 publicado pelo Bureau des Longitudes em 1917 no anuário Connaissance des temps, posteriormente reproduzido no relatório redigido por Morize.

Fonte: gallica.bnf.fr / Bibliothèque nationale de France

2 Por fugir do escopo do trabalho, não nos aprofundaremos aqui sobre a expedição estadunidense que veio a Sobral em 1919. De modo geral, a expedição era organizada pelo Departamento de Magnetismo Terrestre do Carnegie Institution e tinha como objetivo realizar medições acerca do magnetismo terrestre e da eletricidade atmosférica. Para mais informações, conferir MAUCHLY; THOMSON, 1920 e CRISPINO; LIMA, 2018. 
A equipe inglesa determinou em março de 1917 que duas frentes sairiam da Inglaterra para observar o eclipse. A definição da separação das equipes de observação ocorreu em junho de 1918: A primeira - que não nos aprofundaremos aqui - era formada por Eddington e o relojoeiro Edwin Cottingham, direcionada à Ilha do Príncipe. Já a segunda, cujo destino era Sobral, inicialmente contaria com a participação de Charles Davidson e do Padre Aloysius Cortie. A equipe que se dirigia para Sobral foi alterada em novembro de 1918, quando o diretor do Stonyhurst Magnetic Observatory, em Lancashire, adoeceu severamente. "Como Cortie o substituiria, não era um bom momento para deixar a Inglaterra em uma expedição de meses" (GATES JR.; PELLETIER, 2019, n.p., tradução nossa). Assim, Andrew Crommelin foi para Sobral em seu lugar.

Mesmo impossibilitado de viajar para Sobral, o Pe. Cortie foi de grande importância para o desenvolvimento da expedição, principalmente no tocante aos equipamentos que foram utilizados para as observações no nordeste brasileiro. Em agosto de 1914 diversos equipamentos pertencentes aos ingleses não puderam retornar da expedição que foi à Rússia para a observação de um eclipse solar. De acordo com Dyson (1915, p. 14, tradução nossa), graças "ao início da guerra, era impossível para os observadores trazerem de volta os instrumentos com eles, e estes foram deixados no Observatório de Pulkova, a cargo do Dr. Backlund".

A dificuldade enfrentada pelos ingleses para reaver seus equipamentos não foi isolada. Outros astrônomos que também foram observar o eclipse em solo russo em 1914 de diferentes observatórios, como o Observatório Lick (EUA) e o Observatório de Berlin (Alemanha), não conseguiram retirar os telescópios do país, assim como os ingleses. Com o início da guerra, todo o transporte marítimo russo foi direcionado para os esforços de guerra, impossibilitando o deslocamento desses instrumentos. Além disso, quando estourou a Revolução Russa de 1917, as chances de obter os equipamentos para observar o eclipse de 1919 caíram drasticamente. Em tempos de guerra, o trânsito entre nações se torna complicado, sendo esse um desafio enfrentado pelo transnacionalismo científico, ainda mais quando analisamos o trabalho de astrônomos que dependem da observação de eventos astronômicos (como eclipses) que não respeitam fronteiras territoriais, forçando-os a se deslocarem por distintas regiões para realizarem suas pesquisas.

Pe. Cortie participou das observações inglesas do eclipse de 1914, mas não na frente russa. Por ser um padre jesuíta, Cortie foi impedido de entrar no império russo, seguindo para a Suíça para realizar as medições. Sua equipe conseguiu retornar com os equipamentos para o Reino Unido e, de acordo com Kennefick (2019, p. 145, tradução nossa):

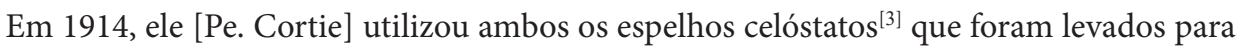
Sobral. Um era o colóstato de dezesseis polegadas pertencente à Royal Astronomical Society (RAS) e utilizado em Sobral com a lente astrográfica. O outro era o celóstato Grubb da RIA [Royal Irish Society], utilizado com a lente de quatro polegadas.

Dessa forma, por já ter trabalhado com ambos os equipamentos, Pe. Cortie informou na mesma reunião em que foi determinada a sua ida à Sobral, em junho de 1918, que já havia providenciado o empréstimo da lente de quatro polegadas e de seu respectivo celóstato com a Royal Irish Society. Embora esse arranjo fosse de posse da sociedade irlandesa, provavelmente o próprio Cortie já estivesse com ele desde 1900, devido ao número de vezes que foi utilizado pelo padre. "Ele o usou em eclipses em 1905, 1911 e 1914. Parece claro que foi ele quem o forneceu à expedição de 1919, e ele pretendera usá-lo originalmente” (KENNEFICK, 2019, p. 146, tradução nossa).

3 Como o transporte para Sobral e Ilha do Príncipe de telescópios completos, com diversas partes móveis, seria muito complexo, foi decidido que a melhor alternativa seria utilizar telescópios fixos, contando com um espelho celóstato como parte móvel. O objetivo dessa peça é realizar a correção da movimentação terrestre, girando o espelho em consonância com a rotação da Terra para que as fotografias de longa exposição (necessárias para o registro de algumas estrelas durante o eclipse) não ficassem borradas, mantendo a imagem das estrelas registradas como pontos nítidos. "Como seria necessária uma medição muito delicada das posições das estrelas, era essencial que o mecanismo de direção fosse particularmente confiável e preciso para produzir uma imagem nítida sem riscos" (KENNEFICK, 2019, p. 111, tradução nossa) 
O celóstato de dezesseis polegadas pertencente a Royal Astronomical Society tinha a capacidade de realizar os ajustes necessários para todas as latitudes que porventura fosse utilizado. Contudo, o celóstato obtido através do empréstimo da Royal Irish Society precisou ser adaptado para ser utilizado no hemisfério sul. "O relógio teve que ser separado do celóstato, montado em uma base de madeira e revertido, para se ajustar ao Hemisfério Sul” (DYSON; EDDINGTON; DAVIDSON, 1920, p. 297, tradução nossa). O fundo para realizar todas as alterações, assim como para organizar a ida dos astrônomos, foi obtido a partir de um pedido realizado por Dyson em 1917 ao Comitê de Subsídios do Governo britânico no valor de $£ 1.100$, sendo $£ 100$ destinadas à instrumentação e $£ 1.000$ para a organização da expedição.

Mesmo com a verba destinada pelo governo inglês, a preparação da expedição inglesa foi conturbada devido ao período de guerra. Um ano após o pronunciamento de Dyson sobre a potencialidade do eclipse a Royal Astronomical Society, os astrônomos não tinham certeza no início de 1918 se eles conseguiriam sair da Inglaterra para observar o fenômeno. No relatório posterior sobre a preparação da expedição, a equipe aponta que nas reuniões de maio e junho de 1918 "foram iniciadas investigações preliminares sobre as instalações portuárias, das quais parecia muito duvidoso que as expedições pudessem ser realizadas” (DYSON; EDDINGTON; DAVIDSON, 1920, p. 295, tradução nossa).

A situação se alterou parcialmente em novembro de 1918 com o Armistício de Compiègne. Embora as chances das duas frentes conseguirem se dirigir aos locais de observação tivessem aumentado consideravelmente, a construção dos aparatos que seriam levados precisava ser apressada. As cabanas, por exemplo, foram construídas pelo engenheiro civil do Royal Naval College, uma vez que o carpinteiro do Observatório Real não havia sido liberado do serviço militar. Na última reunião preparatória da expedição, realizada em fevereiro de 1919, foi organizado o embarque dos equipamentos no navio a vapor Anselm, da companhia Booth Line. O navio partiria de Liverpool com as equipes no dia 8 de março de 1919. Kennefick (2019, p. 154-155) evidencia o fato de o navio utilizado para a viagem não ser um navio militar:

O uso de navios da Marinha Real havia sido bastante comum em expedições anteriores. $\mathrm{O}$ fato de nada nessa direção ser proposto sugere que, logo após a guerra, a marinha não tinha navios de sobra para levar os astrônomos a locais remotos. A reunião final [em fevereiro de 1919] terminou com uma demanda por mais dinheiro do governo (250 libras) e com uma última contribuição da ordem jesuíta. O padre Cortie havia enviado uma carta informando ao comitê que um pedido foi enviado pelos jesuítas portugueses, pedindo aos membros da ordem no Brasil que recebessem a expedição em Sobral. Mas ficou claro que, a partir de então, os membros da expedição estariam operando em grande parte por conta própria.

\section{A preparação da expedição brasileira}

Como já mencionado anteriormente, o relatório redigido por Henrique Morize foi fundamental para que a pequena cidade de Sobral fosse determinada como a melhor cidade no Nordeste brasileiro para a observação do eclipse. Tal relatório foi desenvolvido após o pedido feito por Charles Dillon Perrine ${ }^{4}$, astrônomo estadunidense que, na época, dirigia o Observatório Nacional de Córdoba, na Argentina. Em carta enviada a Morize em junho de 1917, Perrine pedia informações referentes aos locais que poderiam ser utilizados como estações de observação, como clima, meio de acesso e estadia. "As expedições que serão enviadas de todas

4 Perrine também veio ao Brasil em 1912 para a observação do eclipse, mas foi à Cristina (MG), onde, assim como em Passo Quatro, choveu no dia do evento astronômico. A expedição liderada por Perrine foi a única que ainda em 1912 tentou observar a deflexão da luz prevista por Einstein em 1911, no valor de 0,83". Perrine (1917, p. 1, tradução nossa) finaliza a carta que escreveu a Morize dizendo: "Lembro com grande prazer e gratidão, a ajuda muito eficiente que você prestou a todas as expedições que se reuniram para a observação do eclipse que aconteceu no Brasil em 1912. Aproveitando essa oportunidade para expressar minha mais distinta consideração e estima”. 
as partes do mundo, se a guerra permitir, terão que depender de seu Observatório, para quase todo tipo de informações" (PERRINE, 1917, p. 1, tradução nossa)

A partir do pedido feito por Perrine, Morize iniciou o levantamento meteorológico dos possíveis locais de observação e, a partir de sua análise, os resultados "foram enviados por carta a Perrine, à Royal Astronomical Society, e publicados na revista 'L'Astronomie', da Sociedade Astronômica da França” (BARBOZA, 2019, itálicos nossos), além de serem publicados em um livreto na língua portuguesa. Os dados apresentados foram importantes para a definição de Sobral como o sítio de observação das três expedições, a estadunidense, a inglesa e, claramente, a brasileira.

Assim como em 1912, Morize entendia essa expedição como mais do que a simples observação de um evento astronômico. Sua defesa pela ciência pura e sua necessidade de chamar a atenção do governo federal a essa causa persistiam desde aquela época. Em discurso proferido em 1913, na ocasião do lançamento da pedra fundamental do novo edifício do Observatório Nacional, Morize deixa claro esse seu posicionamento:

Poderia, se não temesse vos cançar, multiplicar os exemplos, mas creio que a rapida resenha a que acabo de proceder é sufficiente para demonstrar que as sciencias que vão ser cultivadas nesta amena collina, não são estereis ornatos e que merecem a judiciosa protecção dos estadistas que nos governam. (MORIZE, 2012a [1913], p. 256)

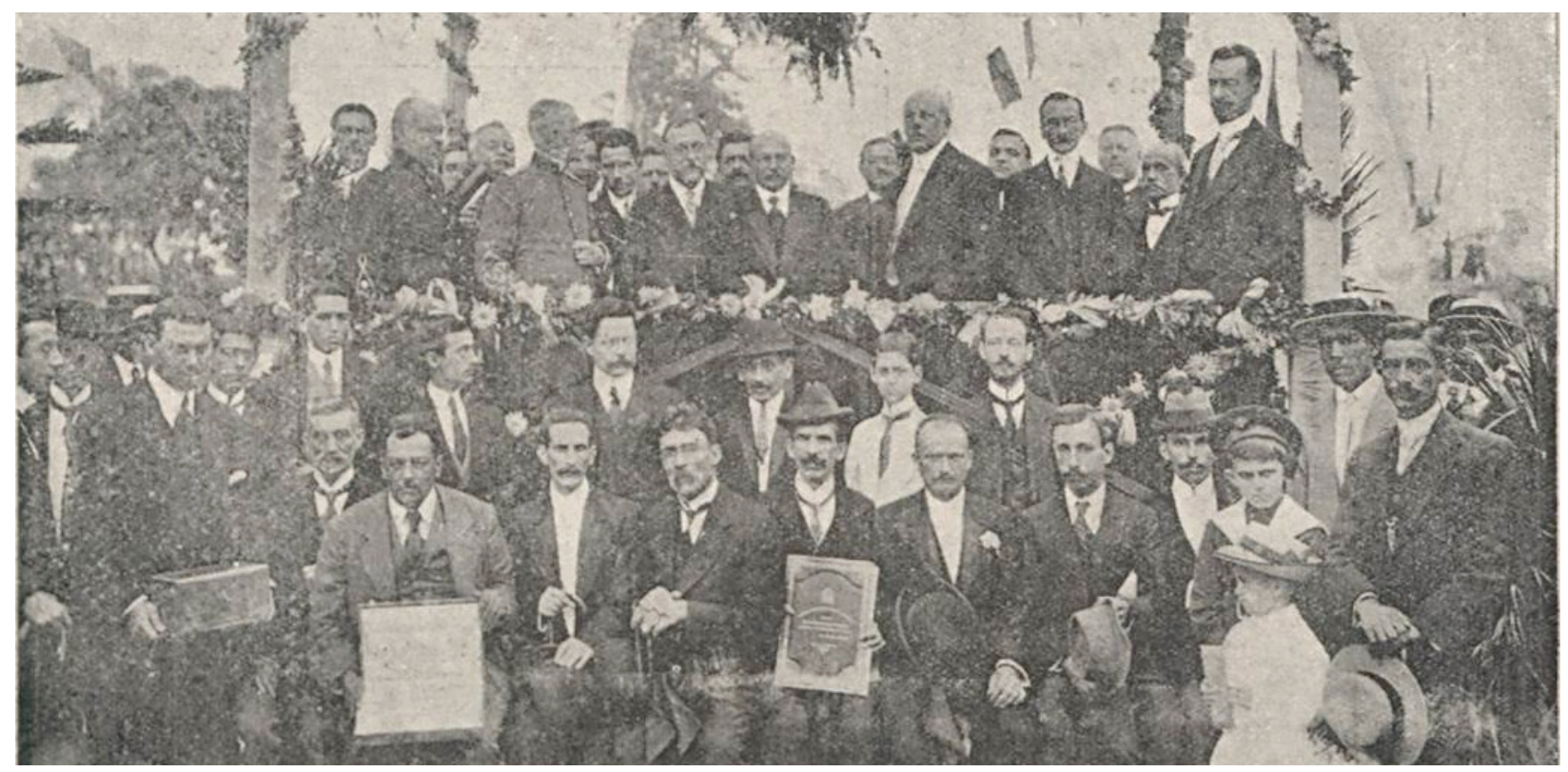

Figura 2 - Foto da inauguração da pedra fundamental publicada pela revista O Malho, em 4 de outubro de 1913, página 9. Fonte: BNDigital

Outro exemplo que merece destaque da luta de Morize pela ciência teórica está em seu discurso proferido no primeiro aniversário de fundação da então Sociedade Brasileira de Sciencias (atual Associação Brasileira de Ciências), cujo presidente era o próprio Morize.

Numa capital rica e prospera como a cidade do Rio de Janeiro, era indispensavel que se fundasse um grêmio, onde aquelles que estudam as questões de sciencia pura pudessem encontrar fraternai agazalho e no qual se promovesse a formação de um ambiente intellectual capaz de transformar a indiferença, ou mesmo em alguns casos a hostilidade, com que a maioria habitualmente acolhe a publicação de tudo quanto não tem o cunho de utilidade material, embora devam saber todos que receberam educação liberal corrente que muitas artes e industrias teem como base pesquizas scientificas e principios abstractos (MORIZE, 2012b [1917], p. 268-269) 
Mesmo depois de sete anos da expedição de 1912 - cuja verba para sua realização resultou da queda de uma janela da antiga sede do Observatório Nacional, um "acidente fortuito" (MORIZE, 1987, p. 144) que liberou verbas havia muito adiadas - e com as constantes declarações e esforços feitos por Morize para que as autoridades governamentais dessem crédito à pesquisa astronômica realizada no país, a burocracia foi um empecilho para a obtenção do dinheiro necessário para a viagem a Sobral, inviabilizando o financiamento público para a expedição brasileira. Para conseguirem chegar à Sobral, recorreram à empresa naval Llyod Brasileiro, cujo diretor era o político Alexandre José Barbosa Lima. Uma representação desse atraso burocrático pode ser vista na revista satírica Careta, do dia 10 de maio de 1919, quando é dito que:

Os astronomos brazileiros tambem deviam partir. Sua partida, porem dependia da acquiescencia do Tribunal de Contas á abertura do credito. Esse nobre instituto entendeu, em sua alta sabedoria, distribuída por nove illuminados cerebros, que não havia pressa, podendo o eclipse sem inconveniente ficar adiado (CARETA, 1919, p. 30)

Diferentemente da equipe inglesa, o objetivo da expedição brasileira para a observação do eclipse de 1919 não se relacionava com a comprovação da recente teoria einsteiniana - embora Morize estivesse a par das consequências que recairia sobre a Física caso ela fosse comprovada. A equipe brasileira pretendia estudar a "forma e disposição da corôa [solar], assim como a indagação espectroscopica de sua composição" (MORIZE, 2012c [1920], p. 317). Parte dos instrumentos que embarcaram para a observação eram os mesmos que foram levados para Passo Quatro no eclipse de 1912. Morize dedica boa parte do relatório redigido acerca dos resultados obtidos para especificar as características de cada um dos telescópios usados, enfatizando quando algum dos componentes havia sido utilizado na cidade mineira.

Os primeiros itens descritos são uma luneta fotográfica com abertura de 15 centímetros e distância focal de 8 metros, juntamente com um celóstato, ambos construídos por Mailhat. "Esse instrumento veio em 1912, por occasião do eclipse daquella data, mas não chegou a ser rectificado completamente, de maneira que para nós era um instrumento novo" (MORIZE, 2012c [1920], p. 319). Porém, mesmo com o Sol centralizado nesse equipamento, a margem deixada na chapa fotográfica era muito justa, o que poderia prejudicar a observação da coroa solar.

Para cobrir tal possibilidade, a equipe brasileira levou para Sobral "outro instrumento, uma pequena equatorial photographica por Steinheil de Munich, e por este reconstruida em 1912 para servir ao eclipse de Passa-Quatro, onde o mão (sic) tempo não permittiu seu uso" (MORIZE, 2012c [1920], p. 319). Já o último instrumento levado para Sobral consistia "de um excellente espectrographo de Hilger, com a optica inteiramente de quartzo e muito transparente [...]. Este instrumento era destinado ao estudo da luz coronal na região equatorial do Sol, proximo ao limbo" (MORIZE, 2012c [1920], p. 320).

A equipe que acompanhou Morize a Sobral era composta dos engenheiros Domingos Fernandes da Costa, Allyrio Hugueney de Mattos, Lélio L. Gama, do meteorologista Luís Rodrigues, do mecânico Arthur de Castro Almeida e do carpinteiro Primo Flores (todos eles assistentes de Morize), além do químico especialista em espectroscopia do Serviço Geológico do Ministério da Agricultura, Indústria e Comércio Thephilo H. Lee (RODRIGUES, 2012).

Contudo, antes de se encontrar com as outras equipes para a observação do eclipse, Morize e Domingos da Costa realizaram uma curta visita à Sobral em 1919 para organizar a recepção de todos, escolhendo os melhores lugares para instalar os sítios de observação, procurando por possíveis alojamentos e conseguindo o apoio local para recepcionar de maneira acolhedora tanto os astrônomos brasileiros quanto os visitantes estrangeiros. No dia 8 de março de 1919, ambos desembarcaram em Camocim, município do Ceará, seguindo para Sobral para acertar esses detalhes. Morize e Costa permaneceram em Sobral por poucos dias nessa viagem, saindo da cidade no dia 18 de março para retornarem ao Rio de Janeiro (A LUCTA, 1919a).

Morize, em um gesto de cordialidade, levou e disponibilizou para a cidade mapas com a trajetória do eclipse, além de dois telescópios para que a população pudesse utilizar no dia do evento. "A ação pode ser 
compreendida ainda como mais um gesto de cortesia para tentar garantir uma estadia tranquila dos demais observadores" (RODRIGUES, 2012, p. 41).

No dia 21 de março foi publicada na capa do jornal A Ordem uma entrevista com Morize intitulada $A$ Ordem ouve o Dr. Morise. Um representante do jornal foi à Pensão Smart, onde Morize estava hospedado durante essa expedição para a organização do evento para que ele concedesse a entrevista. Entre as perguntas, a seguinte é interessante de ressaltarmos:

[Entrevistador] Porque o proximo eclipse despertou tanta attenção ao mundo sientífico? Qual a duração do eclipse?

[Morize] A attenção despertada pelo eclipse de 29 de maio futuro não me parece mais accentuada do que a prestada a analogos phenomenos anteriores. $\mathrm{O}$ caso actual apresenta entretanto o facto notavel de ter a duração da totalidade quase egual ao maximo de duração theoricamente possivel, o que é de $7 \mathrm{~m} 58$ s proximo ao equador e nunca pode ser alcançado, em quanto que o eclipse esperado durará (phase da totalidade) nesta cidade, $5 \mathrm{~m} \mathrm{12s} \mathrm{e} \mathrm{6m} \mathrm{50s} \mathrm{no} \mathrm{Atlantico} \mathrm{(A} \mathrm{ORDEM,} \mathrm{1919,} \mathrm{p.1)}$

Quando sua equipe chegasse à Sobral para a recepção das expedições internacionais, Morize levaria anuários, folhetos e cópias de uma conferência que ministrou na Escola Polytechnica do Rio de Janeiro para presentear a população local.

\section{A Chegada em Sobral e a Observação do Eclipse}

Por se tratar de um grande evento para a cidade de Sobral, houve uma intensa cobertura midiática acerca do eclipse e da chegada dos astrônomos na cidade. A expedição britânica chegou primeiro a Camocim, cidade portuária cearense próxima a Sobral, no dia 29 de abril, partindo para Sobral no dia seguinte. Crommelin (1919, p. 368, tradução nossa) em seu relatório descreve que na chegada em Camocim as "várias apresentações aos agentes de Camocim e Sobral [...] mostraram-se tão eficazes que, a partir do momento em que chegamos a Camocim, estávamos na posição de turistas pessoalmente conduzidos e encontramos tudo organizado para nós". A viagem de Liverpool para Camocim contou com um pequeno desvio; Eddington e Cottingham partiram no mesmo navio que Crommelin e Davidson, aportando na Ilha da Madeira para então seguirem para Ilha do Príncipe, na época colônia de Portugal. Após deixarem os colegas, o navio Anselm seguiu para o Brasil.

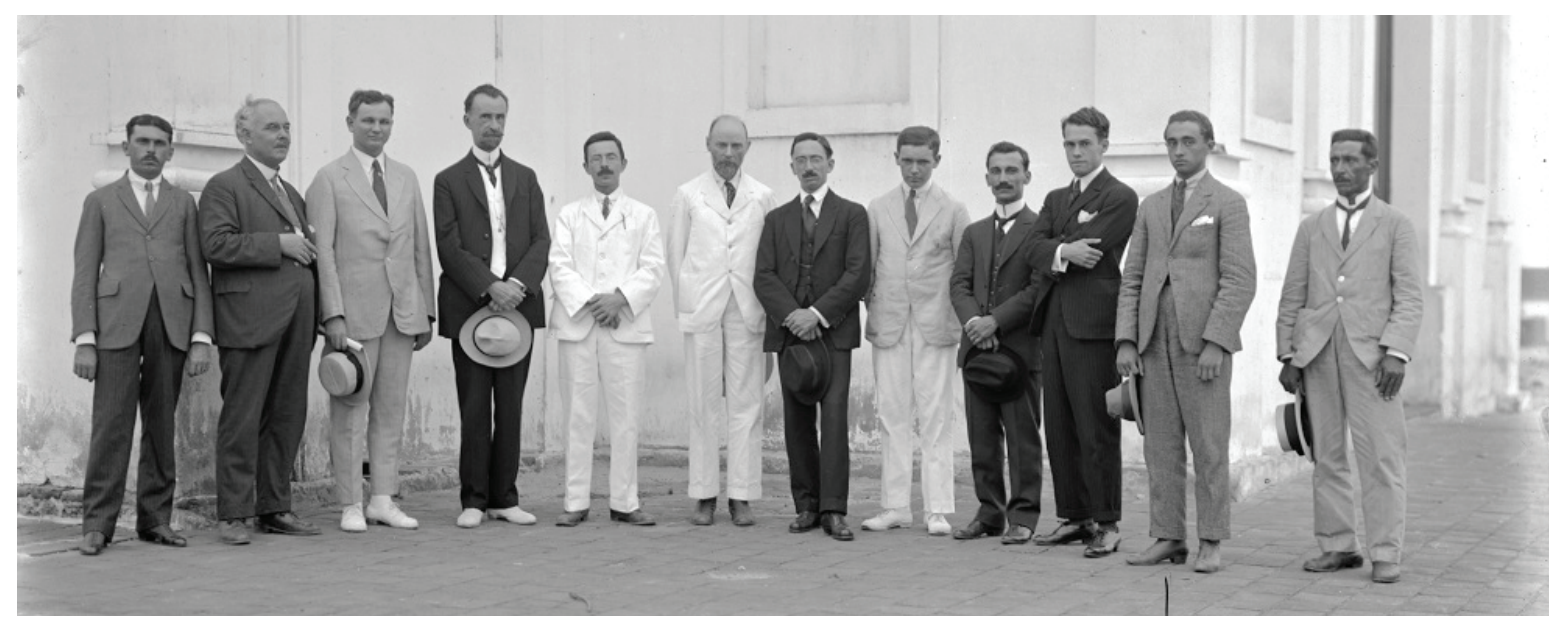

Figura 3 - Comissões que observaram o eclipse em Sobral. Da esquerda para a direita: Luiz Rodrigues (BR), Theophilo Lee (BR), Daniel Wise (USA), Henrique Morize (BR), Charles Davidson (UK), Andrew Crommelin (UK), Allyrio de Mattos (BR), Andrew Thomson (USA), Domingos Costa (BR), Lélio Gama (BR), Antônio C. Lima (BR) e Primo Flores (BR). Fonte: Observatório Nacional 
A equipe brasileira saiu da então capital do país em direção à Fortaleza a bordo do navio João Alfredo no dia 25 de abril de 1919, chegando na capital do Estado do Ceará no dia 7 de maio. Dois dias depois, a comitiva partiria em direção a Sobral, seguindo "conjuntamente com a Commisão Americana que havíamos encontrado em Fortaleza, em um trem especial gentilmente cedido pela Directoria da Estrada" (MORIZE, 2012c [1920], p. 318), chegando em Sobral às 15 horas do mesmo dia.

De abril até o dia do eclipse ocorreu uma extensa cobertura jornalística dos preparativos feitos pelas equipes para a observação do evento. A equipe inglesa descreveu detalhadamente a preparação:

Um local conveniente para a estação do eclipse se oferecia em frente à casa; este era o percurso do Jockey Club e recebíamos uma arquibancada coberta, que achamos mais conveniente para descompactar e guardar e para o trabalho preparatório. Estabelecemos uma linha de meridianos, depois da qual foram construídos pilares de tijolos para os celóstatos e para o tubo de aço do telescópio astrográfico. Enquanto isso estava em andamento, as cabanas estavam sendo erguidas (DYSON; EDDINGTON; DAVIDSON, 1920, p. 297, tradução nossa).

No relatório escrito por Morize e publicado em 1920, boa parte de seu texto se dá sobre os equipamentos utilizados e sua instalação. Contudo é interessante notarmos que Morize, além dos equipamentos para a observação, também levou a Sobral o material necessário para fundar lá uma estação meteorológica:

Tendo sido necessario conduzir instrumentos meteorologicos por causa do eclipse e sendo, por outro lado, Sobral a cidade mais importante do Norte do Ceará, cujo clima merece ser estudado com attenção, resolvi aproveitar os apparelhos trazidos para fundar uma estação de 2a classe, que foi definitivamente installada pelo auxiliar meteorologista Dr. Luiz Rodrigues e confiada ao cuidado do Prefeito municipal, Dr. Jacome de Oliveira (MORIZE, 2012c [1920], p. 327)

Ao chegar na proximidade do evento, os jornais começaram a publicar artigos com um tom apaziguador, pedindo para que a população não se aterrorizasse com o eclipse. Morize compôs diversos dos artigos para jornais nesse tom, dizendo, por exemplo, que as pessoas pouco instruídas poderiam ter "pavor, acompanhado de actos desarrazoados, com gritos, ataques nervosos, fugas para logares escuros, detonações de armas de fogo, repique de sinos etc" (MORIZE apud RODRIGUES, 2012, p. 78).

Na véspera do eclipse, no dia 28 de maio de 1919, o jornal A Lucta publicou um artigo com um pedido de adequação do comportamento da população. Esse artigo, como um todo, é interessante de se analisar, mas destacamos aqui duas passagens. A primeira, referente ao comportamento coletivo esperado:

Os scientistas que aqui se acham para proceder a observação astronômicas recommendam todo silencio nas visinhanças dos observatórios, afim de não perturbar os seus estudos, nem como esperam que ao contrario de outros logares, os sinos não repiquem e nem se queimem foguetes, afim de não perturbar o serviço de photographia (A LUCTA, 1919b, p. 2)

Outra passagem dessa publicação que merece destaque é o seu início, que retoma o ponto da naturalidade do evento e que não há motivos para pânico:

É amanhã o dia do deslumbrante espetaculo cosmico, em que serão essenciaes protagonistas o sol e a lua. O delicioso phenomeno que vem sendo anciosamente esperado pela sciencia e pela curiosidade humana e temido pela ignorancia, terá inicio as 7 horas, $46 \mathrm{~m}$. e 2 s hora official do Rio de Janeiro, nenhuma consequencia nociva tirará o nosso planeta, 
como desarrazoadamente receiam muitas pessoas nervosas e muitos espiritos enclausurados na espessa crosta da ignorancia. Às 8 horas, $48 \mathrm{~m}$ e 8 segundos se verificará a Terra emmersa numa leve abscuridade idêntica o que sucede o ocaso do sol, mas isto é uma coisa banalíssima pela sua naturalidade e não justifica as impressões dolorosas que se prenunciam para amanhã (A LUCTA, 1919b, p. 2)

Vemos, dessa forma, uma faceta interessante do evento de maio de 1919: a expectativa da população quanto ao fenômeno andava em paralelo com a expectativa por observar os astrônomos trabalharem, já que a presença deles provocou diversas alterações na rotina da cidade. "Pode-se dizer que Sobral madrugou na curiosidade do eclypse. Porque, desde logo cedo, era desusado o movimento nas ruas, e grupos esparsos acumulavam-se nos pontos, de referência às praças, de onde o sol era mais visível" (FOLHA DO LITTORAL, 1919, p. 1).

\section{Considerações Finais}

Os resultados obtidos pela expedição inglesa a partir da observação de Sobral e Ilha do Príncipe são amplamente conhecidos, principalmente para aqueles que estudam a história da Teoria da Relatividade: na reunião conjunta entre a Royal Society e a Royal Astronomical Society do dia 6 de novembro de 1919, Dyson, Crommelin e Eddington apresentaram aos seus pares os resultados que confirmavam a predição feita por Einstein em 1916. Já no dia seguinte, dia 7 de novembro, o jornal londrino The Times publicou a notícia: REVOLUTION IN SCIENCE / NEW THEORY OF THE UNIVERSE / NEWTONIAN IDEAS OVERTHROWN. "Nesta edição do Times de Londres encontramos a primeira notícia dada a um mundo devastado pela guerra dos acontecimentos nas reuniões conjuntas das sociedades no dia anterior" (PAIS, 1993, p. 373).

A notícia de uma expedição britânica confirmando uma teoria alemã pouco depois do final da Primeira Guerra possui um grande peso, seja para a aceitação da Teoria da Relatividade Geral, seja para a construção da imagem que temos até os dias atuais de Einstein. Contudo, o anúncio também possui um grande valor quando pensamos sobre a imagem de Eddington:

Ele era um defensor sem reservas da teoria da relatividade de Einstein, dedicou vários meses de sua vida a testar uma de suas previsões e trabalhou duro para obter elogios do público por seus esforços. Seus esforços como publicitário serviram não apenas para convencer os cientistas e a sociedade de que os membros do JPEC estariam realizando um experimento crucial, mas também beneficiaram sua causa especificamente ao reforçar sua credibilidade como praticante de um experimento desafiador (SPONSEL, 2002, p. 466, tradução nossa)

Embora Eddington fosse um dos principais defensores da Teoria da Relatividade Geral, apresentamos ao longo de nosso texto que ele precisou se aliar com outras grandes figuras dentro da sociedade científica para que a expedição pudesse ser desenvolvida. O prestígio de Dyson, por ser Astrônomo Real, por exemplo, auxiliou na obtenção dos fundos necessários com o Comitê de Subsídios do Governo britânico; Padre Cortie e seu contato com a Royal Irish Society possibilitou a obtenção de equipamentos irlandeses para suprir os equipamentos que estavam confiscados em território russo após o início da guerra; o contato entre Eddington e Morize, iniciado em 1912 em Passa Quatro, para receber seus colegas ingleses.

Da mesma forma que a expedição inglesa dependia de uma recepção em Sobral para poder realizar suas observações, a equipe brasileira também precisava que as expedições fossem bem recebidas. Os esforços empreendidos por Morize para que isso acontecesse vinham não só do fato de que o eclipse também seria observado pela equipe nacional, mas muito pela sua defesa da ciência pura e teórica, além de sua necessidade 
de chamar a atenção das autoridades governamentais para as pesquisas realizadas pelo Observatório Nacional. Exemplos das dificuldades financeiras com as quais o Observatório tinha que lidar são visíveis quando recordamos do "incidente fortuito" que possibilitou a expedição de 1912 e do atraso burocrático de 1919 que resultou no pedido à empresa naval Llyod Brasileiro.

Embora a equipe inglesa também dependesse de um navio comercial para viajar ao Brasil, o contexto de cada uma das comissões era bem distinto: enquanto a equipe inglesa recorresse a isso devido à falta de navegações militares em um contexto de fim de guerra, no caso brasileiro essa dependência era o resultado da falta de verbas públicas para a realização da viagem. Mesmo com as dificuldades, a comitiva brasileira conseguiu bons resultados, tanto na organização da receptiva das expedições estrangeiras, quando no âmbito observacional. Morize inicia o último parágrafo de seu relatório dizendo:

Tendo assim rapidamente passado em revista a grande quantidade de factos agitados ou de problemas resolvidos pela observação do eclipse de 29 de Maio, não posso terminar esta palestra sem cordialmente agradecer aos meus distinctos collegas e collaboradores a pesada tarefa que tomaram sobre si, para que fosse, em circumstancias difficeis, levada a bem, a missão que nos foi confiada (MORIZE, 2012c [1920], p. 328)

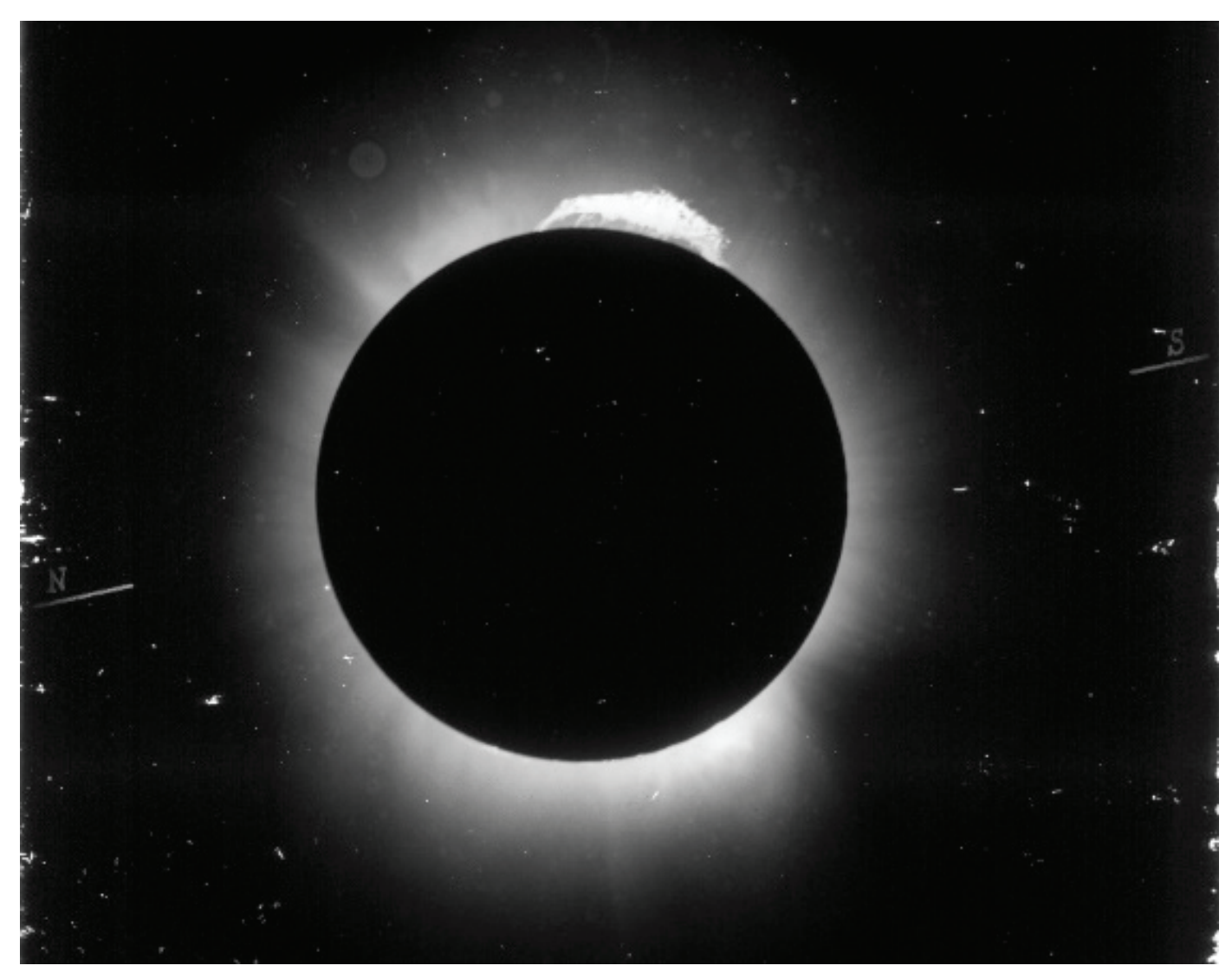

Figura 4 - Fragmento da foto obtida pela comitiva brasileira com a luneta de Mailhat, onde uma protuberância na coroa solar (a protuberância do Tamanduá) é visível.

Fonte: Museu de Astronomia e Ciências Afins

Mesmo que a participação brasileira na organização da recepção das expedições estrangeiras e na observação do eclipse de 29 de maio de 1919 tenha chamado a atenção populacional e governamental para a importância do desenvolvimento científico nacional, a formalização de um patrocínio público demorou mais de trinta anos para ocorrer, com a proclamação da Lei no 1.310 em 1951, criando assim o Conselho Nacional de Pesquisas (CNPq), projeto esse que começou a ser debatido em 1949. 
Mostramos no presente artigo diversos fatores que exemplificam as complexidades que podem ser levantadas a partir do episódio concernente ao eclipse solar de 1919. O fato dos eclipses não respeitarem fronteiras territoriais potencializa os estudos feitos a partir de uma visão transnacional, já que aqueles que se propõem a observá-los constantemente necessitam realizar o trânsito entre nações. No caso do eclipse de 1919, a realização desse trânsito, principalmente no caso inglês, foi dificultada pelo contexto de guerra no qual a equipe de cientistas se encontrava.

Obviamente, toda essa complexidade não poderia ser esgotada em um único trabalho, mas esperamos ter alcançado o que foi por nós proposto. Nos focamos não só nos quesitos relevantes para cada um dos contextos sociais, mas na confluência que se deu em torno desse evento. Vimos como as equipes inglesa e brasileira estabeleceram suas relações, anos antes, em 1912, e como esse contato foi importante para o andamento da observação do eclipse de 1919. Além disso, apresentamos como cada uma das equipes de diferentes nacionalidades desempenhou um papel importante para que Sobral se tornasse um ponto relevante dentro do escopo da História da Astronomia e da Física e como os resultados por elas obtidos alteraram profundamente o desenvolvimento das pesquisas de todo o mundo.

\section{Referências Bibliográficas}

A LUCTA. O ECLIPSE, Sobral, p. 2, 12 de Mar. 1919 (1919a). Disponível em: <http://memoria.bn.br/pdf/720763/ per720763_1919_00254.pdf >. Acesso em: 5 de jan. 2020, às 13:12.

O ECLIPSE, Sobral, p. 2, 28 de Mai. 1919 (1919b). Disponível em: <http://memoria.bn.br/pdf/720763/ per720763_1919_00266.pdf>. Acesso em: 5 de jan. 2020, às 13:15.

A ORDEM. A Ordem Ouve o Dr. Morise, Sobral, p. 1, 21 de Mar. 1919. Disponível em: <http://memoria.bn.br/DOCREADER/234702/203>. Acesso em: 5 de jan. 2020, às 13:16.

BARBOZA, C. H. M. Ciência e natureza nas expedições astronômicas para o Brasil (1850-1920). Boletim do Museu Paraense Emílio Goeldi. Ciências Humanas, v. 5, n. 2, p. 273-294, 2010.

. O eclipse em Sobral e os desafios da Astronomia no Brasil em 1919. Boletim da Sociedade Brasileira de História da Ciência, v. 21, 2019. Disponível em: <https://www.sbhc.org.br/conteudo/view?ID_CONTEUDO=1073>. Acesso em: 5 de jan. 2020, às 13:17.

BROWN, J. A. C. Techniques of Persuasion, from propaganda to brainwashing. Londres: Penguin Books, 1963.

CARETA. Navegação e Astronomia, Rio de Janeiro, p. 30, 10 de Mai. 1919. Disponível em: <http://objdigital.bn.br/acervo_digital/div_periodicos/careta/careta_1919/careta_1919_568.pdf> Acesso em: 5 de jan. 2020, às 13:20.

CHANDRASEKHAR, S. Verifying the Theory of Relativity. Notes and Records of the Royal Society of London, v. 30, $\mathrm{n}$. 2, p. 249-260, 1976.

CRISPINO, L. C. B.; LIMA, M. C. Expedição norte-americana e iconografia inédita de Sobral em 1919. Revista Brasileira de Ensino de Física, v. 40, n. 1, 2018.

CROMMELIN, A. C. D. The eclipse expedition to Sobral. The Observatory, v. 42, p. 368-371, 1919.

DYSON, F. W. Report of the Astronomer Royal to the Board of Visitors of the Royal Observatory, Greenwich. Greenwich Observations in Astronomy, Magnetism and Meteorology Made at the Royal Observatory, s. 2, v. 76, p. H1-H24, 1915.

On the opportunity afforded by the eclipse of 1919 May 29 of verifying Einstein's theory of gravitation. Monthly Notices of the Royal Astronomical Society, v. 77, p. 445, 1917.

. [Carta] 24. Nov. 1919, Londres [para] MORIZE, H. C. 1f. Disponível em: <http://www.mast.br/sobral/img-documentacao.html>. Acesso em: 5 de jan. 2020, às 13:22.

DYSON, F. W.; EDDINGTON, A. S.; DAVIDSON, C. A determination of the deflection of light by the sun's gravitational field, from observations made at the total eclipse of May 29, 1919. Philosophical Transactions of the Royal Society of London. Series A, Containing Papers of a Mathematical or Physical Character, v. 220, p. 291-333, 1920.

EINSTEIN, A. Über den Einfluß der Schwerkraft auf die Ausbreitung des Lichtes. Annalen der Physik, v. 340, n. 10, p. 898-908, 1911. 
Die Grundlage der allgemeinen Relativitätstheorie. Annalen der Physik, v. 354, n. 7, p. 769-822, 1916.

FOLHA DO LITTORAL. De Sobral - O ECLYPSE DO DIA 29 (do correspondente), Camocim, 8 de Jun. 1919. Disponível em: <http://memoria.bn.br/pdf/800198/per800198_1919_00051.pdf>. Acesso em: 5 de jan. 2020, às 13:23.

GATES JR, S. J., PELLETIER, C. Proving Einstein right: the daring expeditions that changed how we look at the universe. Nova Iorque: PublicAffairs, 2019. E-book.

GLICK, T. F. (Ed.). The Comparative Reception of Relativity. Dordrecht: Springer, 1987.

KRAGH, H. Quantum generations: A history of physics in the twentieth century. Princeton: Princeton University Press, 2002.

KEVLES, D. J. Albert Einstein: Relativity, war, and fame. In: PRINCETON UNIVERSITY

PRESS. A Century in Books Press: Princeton University Press 1905-2005. Princeton: Princeton University Press, p. 115$24,2005$.

KENNEFICK, D. No Shadow of a Doubt: The 1919 Eclipse that Confirmed Einstein's Theory of Relativity. Princeton: Princeton University Press, 2019.

MARQUIS, A. G. Words as weapons: propaganda in Britain and Germany during the First World War. Journal of Contemporary History, v. 13, n. 3, p. 467-498, 1978.

MAUCHLY, S. J.; THOMSON, A. Results of atmospheric-electric observations made at Sobral, Brazil, during the total solar eclipse of May 29, 1919. Terrestrial Magnetism and Atmospheric Electricity, v. 25, n. 2, p. 41-48, 1920.

MORIZE, H. C. Discurso proferido pelo Dr. Henrique Morize, Diretor do Observatório Nacional, por ocasião do lançamento da pedra fundamental dos novos edifícios do mesmo Observatório, em 28 de Setembro de 1913. [1913] In: VIDEIRA, A. P. (coord.) Henrique Morize, Coleção Memória do Saber. Rio de Janeiro: Fundação Miguel de Cervantes, p. 249-259, 2012a.

. Discurso proferido pelo Presidente Prof. H. Morize, na Sessão Plena de 15 de junho de 1917. [1917] In: VIDEIRA, A. P. (coord.) Henrique Morize, Coleção Memória do Saber. Rio de Janeiro: Fundação Miguel de Cervantes, p. 267-274, 2012b.

Resultados obtidos pela commissão brasileira do eclipse de 29 de Maio de 1919. [1920] In: VIDEIRA, A. P. (coord.) Henrique Morize, Coleção Memória do Saber. Rio de Janeiro: Fundação Miguel de Cervantes, p. 312-328, 2012c.

Observatório Astronômico - Um século de história (1827-1927). Rio de Janeiro: Salamandra, 1987.

PAIS, A. Subtil é o Senhor: Vida e pensamento de Albert Einstein. Lisboa: Gradiva, 1993.

PERRINE, C. D. [Carta] 1. Jun. 1917, Córdoba [para] MORIZE, H. C. 1f. Disponível em: <http://www.mast.br/sobral/ img-documentacao.html>. Acesso em: 5 de jan. 2020, às 13:25.

RODRIGUES, J. M. Entre telescópios e potes de barro: O eclipse solar e as expedições científicas em 1919/Sobral-CE. 2012. Dissertação (Mestrado em História Social) - Pós-Graduação em História Social, Universidade Federal do Ceará, Fortaleza, 2012.

SPONSEL, A. Constructing a 'revolution in science': the campaign to promote a favourable reception for the 1919 solar eclipse experiments. The British journal for the history of science, v. 35, n. 4, p. 439-467, 2002.

STANLEY, M. Einstein's war: the birth of relativity amid the vicious nationalism of World War I. Nova Iorque: Dutton, 2019.

VIDEIRA, A. A. P. A participação brasileira no eclipse solar total de maio de 1919: observando a coroa solar para melhor defender a ciência. Ciência e Cultura, v. 71, n. 3, p. 23-26, 2019. 